\title{
A quantitative method for blood lipoproteins using cellulose acetate electrophoresis
}

\author{
H. N. MAGNANI ${ }^{1}$ AND A. N. HOWARD \\ From the Departments of Pathology and Investigative Medicine, University of Cambridge, England
}

SYNOPSIS A rapid, inexpensive, and quantitative method is described for obtaining the levels of plasma very low, low, and high density lipoproteins using cellulose acetate electrophoresis and lipid assays without prior separation by ultracentrifuge or other techniques. It involves separation of the lipoproteins by cellulose acetate electrophoresis, followed by their identification with the ozoneSchiff reaction. The total lipoprotein concentration is estimated from the total plasma phospholipid, and the percentage of each component obtained by densitometric analysis of the stained electrophoretograms, using reflected light. For samples with a raised level of very low density lipoprotein, plasma triglyceride analysis is also required.

The results obtained by the cellulose acetate electrophoresis method are in good agreement with those by the analytical ultracentrifuge and the preparative ultracentrifuge with refractometry. The theoretical assumptions on which the method is based have been shown to be valid.

In recent years many attempts have been made to bring some order to the study of lipoproteins, most notable being the typing system using paper electrophoresis devised by Fredrickson, Levy, and Lees (1967). This system has drawbacks as it gives limited information, especially to those who may require to differentiate various subtypes of lipoprotein. Improvements in electrophoresis giving clearer separations have been made by using either agarose alone (Papadopoulos and Kintzios, 1969) or in combination with agar (Noble, 1968) and cellulose acetate (Winkelman and Ibbott, 1969; Winkelman, Ibbott, Sobel, and Wybenga, 1969; Fletcher and Styliou, 1970) as the support media instead of paper. However, without ultracentrifugal analysis, it is at present impossible to place electrophoresis of lipoproteins on a quantitative basis. Chin and Blankenhorn (1968) have attempted to make cellulose acetate electrophoresis quantitative but the lipidsoluble fat dyes they used do not stain the lipoproteins quantitatively.

An improved method of staining is that devised by Kohn (1961 and 1966) in which ozone reacts with the carbon-carbon double bonds of unsaturated fatty acids to form aldehydes which give a red colour with Schiff's reagent (Pearse, 1968). Low density and very low density are slightly more unsaturated than high density lipoproteins but the difference in total Received for publication 4 March 1971.

'Present address: Oklahoma Medical Research Institute, 825 NE 13th St, Oklahoma City, USA. number of double bonds does not exceed $10 \%$ and may be less (Blaton et al, in preparation; Blaton and Peeters, 1968). Densitometric analysis of stained strips therefore gives a reasonable estimation of the quantity of lipid present in each band. Since the lipid: protein ratios of the individual lipoproteins have been measured (Table I) all that is further required for complete lipoprotein analysis is the total plasma lipoprotein concentration.

After a perusal of the literature (Table I) it was noted that the phosphorus content of the high, low, and very low density lipoproteins (of $S_{\mathrm{f}}<100$ ) was approximately $23 \cdot 5,24 \cdot 5$, and $23 \cdot 5$, respectively, when expressed as a percentage of the total lipoprotein mass. Thus, the lipid phosphorus content of plasma or serum from fasted individuals should reflect the total lipoprotein content. Experiments were therefore undertaken to study the electrophoretic migration of plasma lipoprotein on cellulose acetate with the object of developing a quantitative method based on chemical staining of the electrophoretogram and a total plasma phospholipid determination.

\section{Materials and Methods}

COLLECTION AND TREATMENT OF BLOOD

Human plasma or serum was obtained from normal and hyperlipaemic subjects and included types II and IV of Fredrickson et al (1967). 


\begin{tabular}{|c|c|c|c|c|c|c|c|c|}
\hline \multirow[t]{2}{*}{ Lipoprotein Moiety } & \multicolumn{2}{|c|}{$\begin{array}{l}\text { Chylomicrons } \\
\left(S_{f}>400\right)\end{array}$} & \multicolumn{2}{|c|}{$\begin{array}{l}V L D L \\
\left(S_{f}<100\right)\end{array}$} & \multicolumn{2}{|l|}{$L D L$} & \multicolumn{2}{|l|}{$H D L$} \\
\hline & $\% L P$ & $\% T L$ & $\% L P$ & $\% T L$ & $\% L P$ & $\% T L$ & $\% L P$ & $\% T L$ \\
\hline $\begin{array}{l}\text { Protein } \\
\text { Total cholesterol } \\
\text { Total phospholipid } \\
\text { Triglyceride }\end{array}$ & $\begin{array}{l}0.5 \\
2 \\
3 \\
95\end{array}$ & $\begin{array}{r}- \\
2 \\
3 \\
95\end{array}$ & $\begin{array}{c}6 \\
18 \cdot 8 \\
23 \cdot 5 \\
51 \cdot 7\end{array}$ & $\begin{array}{l}-20 \\
25 \\
55\end{array}$ & $\begin{array}{l}21 \\
43 \cdot 5 \\
24 \cdot 5 \\
11 \cdot 1\end{array}$ & $\begin{array}{l}-55 \\
31 \\
14\end{array}$ & $\begin{array}{l}50 \\
18 \cdot 0 \\
23 \cdot 5 \\
8 \cdot 5\end{array}$ & $\begin{array}{l}\overline{36} \\
47 \\
17\end{array}$ \\
\hline
\end{tabular}

Table I Composition of human plasma lipoproteins ${ }^{1}$

1Cornwell (1967); Fredrickson and Lees (1966); Levy and Fredrickson (1965); Lindgren, Hatch, and Freeman (1967); Olson and Vester (1960); Peeters and Blaton (1968); Skipski, Barclay, Barclay, Fetzer, Good, and Archibald (1967); Stamler, Berkson, Young, Lindberg, Hall, Mojonnier, and Andelman (1963); Walton and Darke (1964).

Blood was collected after an overnight fast, haemolysed specimens being discarded. Assays for lipoprotein were performed within 48 hours, if possible, but intervals of up to several months did not appear to affect the results provided the samples were from fasted individuals, and were stored at $+4^{\circ} \mathrm{C}$.

\section{ANALYTICAL ULTRACENTRIFUGE}

The analyses of 13 samples were performed by Drs Strisower, Adamson, and Lindgren at the Donner Laboratories, Berkeley, California, USA, on samples kept at $4^{\circ} \mathrm{C}$ and transported by air to the Cambridge Laboratories.

\section{PREPARATIVE ULTRACENTRIFUGE REFRAC- TOMETRY}

Employing the method of Lindgren and his coworkers (Lindgren and Gofman, 1957; Lindgren and Nichols, 1960; Lindgren, Nichols, Freeman, Wills, Wing, and Gullberg, 1964) the three main classes of lipoproteins were assayed.

\section{CELLULOSE ACETATE ELECTROPHORESIS Electrophoresis}

Sephraphore III strips, $6.75 \times 1.0$ in. (Gelman Instrument Company, Ann Arbor, Michigan, USA), were used for the electrophoresis in a Gelman de luxe tank. Samples of 2 to $4 \mu \mathrm{l}$ were applied to the strips with a Gelman applicator and electrophoresis was carried out in an $0.00238 \mathrm{M}$ Gelman high resolution tris-barbital-sodium barbital buffer, $p \mathbf{H}$ 8.8 , at room temperature $\left(19-23^{\circ} \mathrm{C}\right)$ at 325 volts, applied by a constant voltage power pack (Heathkit, Daystrom Ltd., Gloucester, England; model MSPIM), for $85 \mathrm{~min}$, at a current of $1.4 \mathrm{~m} / \mathrm{amps} / \mathrm{strip}$.

\section{Staining of the electrophoretograms}

Identification of the lipid-containing bands was achieved by dividing the strips longitudinally and staining one half for protein and the other for lipid. The halves were then realigned. Any small differential shrinkage of the strips did not impair the identification.

Proteins were stained by the standard technique using amido schwartz (Bodman, 1960). Lipids were stained according to the method of Kohn (1961 and 1966). The strips were exposed to ozone for two hours at room temperature and to the Schiff's reagent for six hours at $+4^{\circ} \mathrm{C}$ and then stored in $0.1 \mathrm{~N} \mathrm{HCl}$. An example of a fully stained strip is shown in Figure 1.

Densitometric analysis of the electrophoretograms The stained half-strips, whilst wet, were paired, aligning the protein stain with the corresponding lipoprotein stain as shown in Figure 1. They were then examined by reflected light in a chromoscan (Joyce Loebl Instruments, Halifax, England), using a $\frac{1}{2} \mathrm{~mm} \times 5 \mathrm{~mm}$ slit for the lipoprotein and a $\frac{1}{2} \mathrm{~mm}$ diameter aperture for the protein. Using the auto-

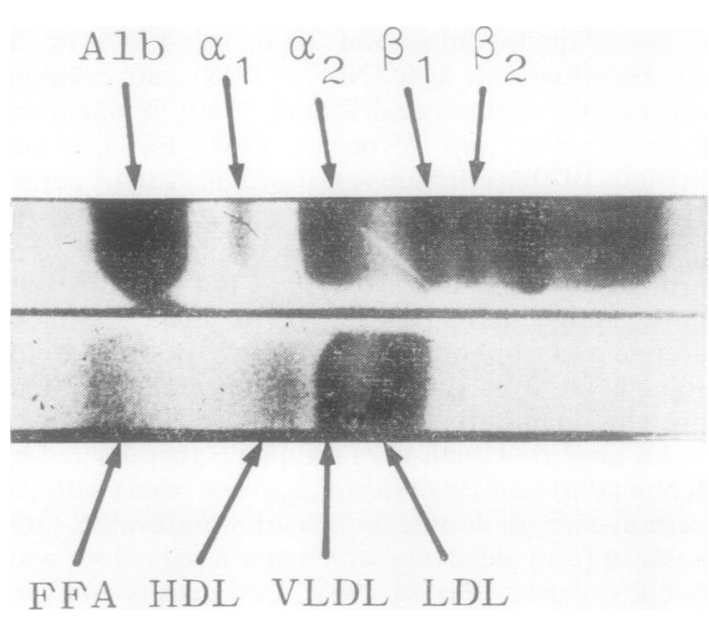

Fig. 1 Cellulose acetate electrophoretogram of plasma showing protein bands stained with amido schwartz (A) and lipoproteins with Schiff's reaction (B). 
matic integrator, figures for the areas representing high, low, and very low density lipoproteins and chylomicrons, were noted.

\section{Lipid assays}

Any technique for lipid measurement can be used for the assay procedure for lipoprotein. In early experiments lipid separation was carried out by thinlayer chromatography (TLC) and subsequent determination of cholesterol (Babson, Shapiro, and Phillips, 1962), phospholipids (Bartlett, 1959), and triglycerides (Marsh and Weinstein, 1966). In a later series of experiments, the phospholipids were assayed directly from the lipid extract without TLC, by extracting the plasma according to the method of Folch, Lees, and Sloane-Stanley (1957), then analysing lipid phosphorus (Bartlett, 1959). The triglyceride (Lofland, 1964) and cholesterol were also assayed, using an autoanalyser.

\section{Percentage concentration of lipoprotein}

From the data in Table I the factors relating lipid content of lipoprotein to total lipoprotein mass were calculated, eg, 2.00 for high density, 1.265 for low density and 1.06 for very low density, 1.00 for chylomicrons and lipomicrons. The contribution of

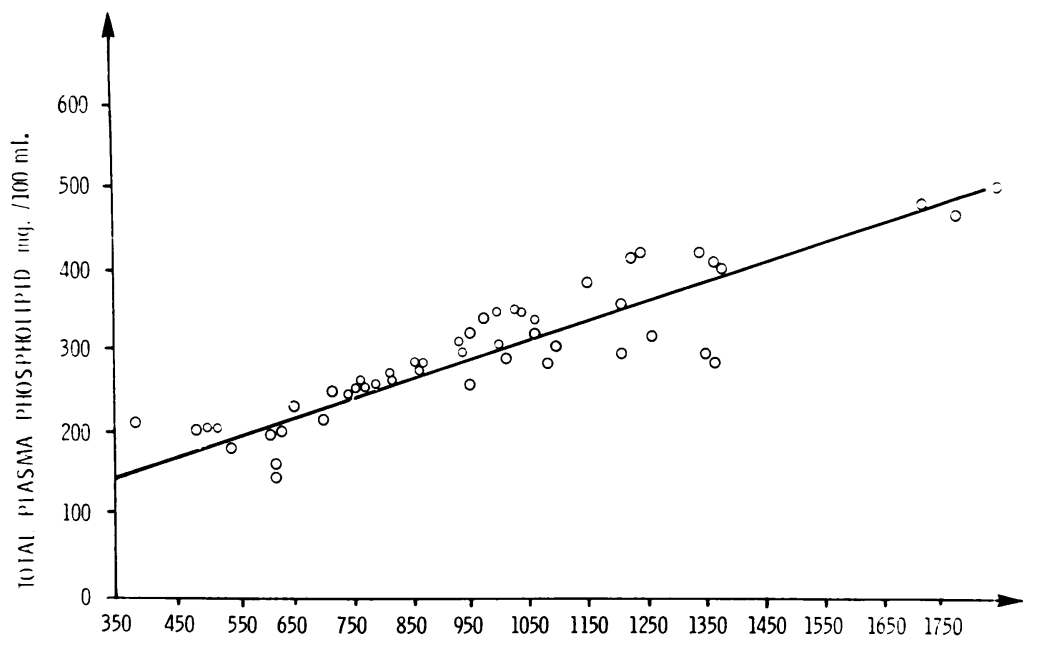

Fig. 2a The relationship of total lipoprotein to lipid phosphorus. Number of observations 52 ; slope $0 \cdot 243$; correlation coefficient $0 \cdot 820$; intercept 64.5; $\mathrm{P}<0.001$.

TOTAL PLASMA LIPOPROTEIN mg. / $100 \mathrm{mil}$.

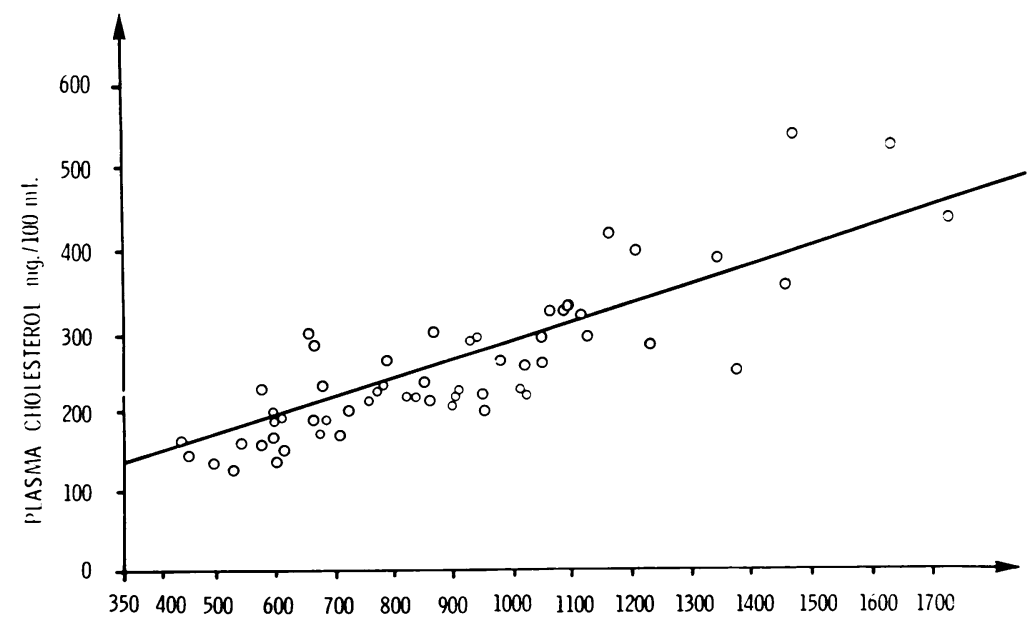

Fig. 2b The relationship of total lipoprotein to plasma cholesterol. Number of observations 53 ; slope 0.253; correlation coefficient $0 \cdot 644$; intercept $35 \cdot 3$; $\mathbf{P}<0.001$. 


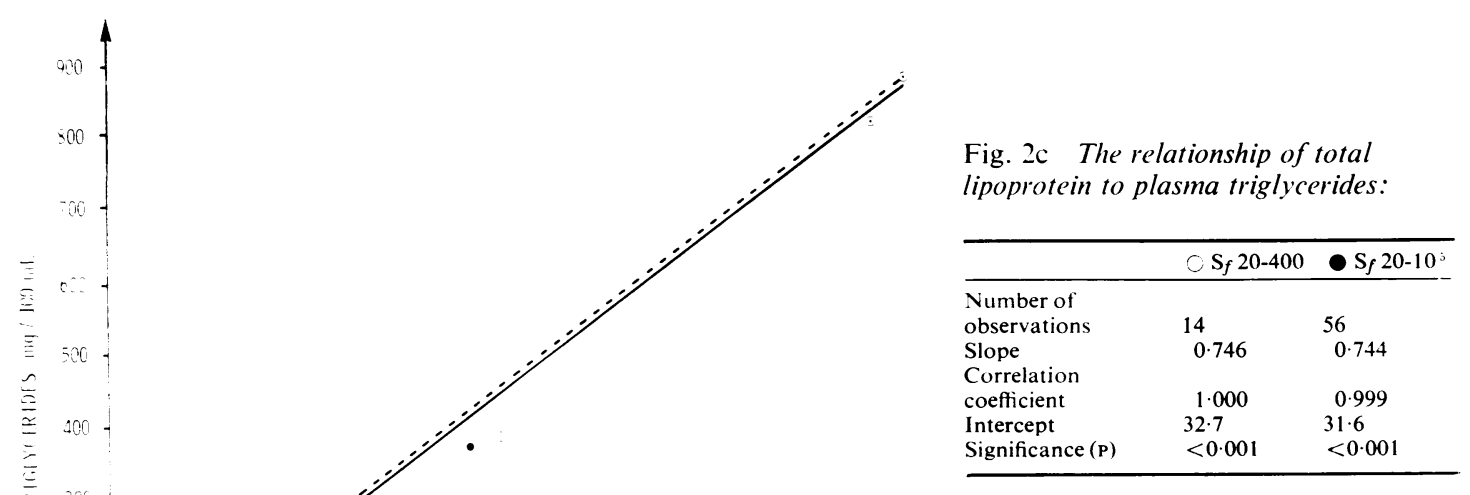

each lipoprotein component to the total concentration was calculated by multiplying the respective peak area on the chromoscan by the above factors, and then expressing them as a percentage.

\section{Total plasma or serum lipoprotein}

Both the phosphorus and total cholesterol concentrations were found to correlate significantly ${ }^{1}$ with the total liproprotein concentration (expressed as the sum of the very low $\left(S_{\mathrm{f}} 20-100\right)+$ low + high density concentrations of lipoprotein), as shown in Figs. 2a and $b$. Thus, accurate analysis of these lipids provides a measurement of the total lipoprotein $\left(S_{f} 0-100\right)$. Since the phosphorus assay showed the higher correlation coefficient, it became the method of choice. Liproproteins were therefore calculated from a prepared standard graph relating lipid phosphorus to lipoprotein. ${ }^{2}$

The triglyceride concentration was found to be directly related to the total very low density lipoprotein ( $\left.S_{f} 20-400\right)$ (Fig. 2c). When this concentration was above $100 \mathrm{mg} / 100 \mathrm{ml}$, the total lipoprotein derived from the phosphorus assay was unreliable (because the percentage phosphorus in the very low density lipoprotein $S_{\mathrm{f}}>100$ is inversely related to the $S_{f}$ value). In these cases, the very low density lipoprotein was estimated separately from the triglyceride concentration ${ }^{2}$ (Fig. 2c) and then re-used in deriving a 'corrected total lipoprotein' as follows:

${ }^{1}$ Using a standard statistical method as, for instance, that described by Quenouille (1966).

${ }^{2}$ There is no need for other investigators to establish their own calibration curve since it is justifiable to use the data as shown in Figure 2. from the sum of the very low density lipoprotein (estimated by triglyceride assay) and the total lipoprotein (estimated by phosphorus assay) was subtracted $100 \mathrm{mg} / 100 \mathrm{ml}$ (this figure being the approximate amount of very low density lipoprotein which the phosphorus assay estimates). Such corrected total lipoprotein then agrees well with the ultracentrifuge assays. In a few samples with very low density lipoprotein concentrations over $100 \mathrm{mg}$ / $100 \mathrm{ml}$, the excess had a predominating $\mathrm{S}_{f}$ rate in the 20-100 region. Such very low density lipoproteins were accurately accounted for by the phosphorus assay and did not require correction. These samples were distinguished by their electrophoretograms because the very low density ran closer to the low density lipoprotein or became incorporated into its leading edge.

\section{Calculation of each lipoprotein concentration}

The concentration $(\mathrm{mg} / 100 \mathrm{ml})$ of each class of lipoprotein was found by multiplying the percentage composition with the total lipoprotein calculated from the phosphorus assay. When the very low density lipoprotein concentration was above $100 \mathrm{mg} /$ $100 \mathrm{ml}$ the corrected lipoprotein concentration using a triglyceride analysis was employed as described above.

\section{Results}

The total number of human samples studied was 111 . All samples had the lipoprotein assayed by prepara- 
tive ultracentrifuge and refractometry and 60 of these were examined by cellulose acetate electrophoresis.

ELECTROPHORETIC MIGRATION OF LIPOPROTEIN ON CELLULOSE ACETATE

The assignment of bands was achieved by correlating known lipoprotein fractions and samples from which they had been removed with their migration patterns given by the ozone-Schiff-stained electrophoretograms. Five main bands were observed (Fig. 3). The lipomicrons of probable $S_{\mathrm{f}} 400-10^{3}$ migrated in the albumin to $\alpha_{2}$ globulin region, the actual position depending to some extent on their predominating $S_{\mathbf{f}}$ rate. The five bands were as follows: (1) chylomicrons $S_{\mathrm{f}} 10^{3}-10^{5} ;(2)$ very low density lipoprotein, Sf $20-10^{3}$; (3) low density lipoprotein $\mathrm{S}_{\mathrm{f}} 0-20$; (4) total high density lipoprotein $\mathrm{F}_{1.20} 0-9$; and (5) albumin free fatty acids.

Some lipoprotein fractions, ie, very low density lipoprotein, were not demonstrable on each electrophoretogram due to their low concentration or absence. Occasionally one class overlapped another migrating at approximately the same rate; this was evident not only in those samples containing a high concentration of very low density lipoprotein with $S_{\mathbf{f}}>100$, but also in the many samples which contained such small amounts of very low density lipoprotein $S_{\mathrm{f}}$ 20-100 that it became incorporated into the low density peak.

Frequently the electrophoretogram contained three peaks only, one representing the albumin free fatty acid, a second consisting of low density lipoprotein in the $\beta_{1} / \beta_{2}$ region, and the third in the $\alpha_{1} / \alpha_{2}$ region. The nature of this third peak could only be ascertained by considering the phosphorus and triglyceride levels. If the phosphorus were normal or raised and the triglyceride normal or only slightly raised, then the band was high density lipoprotein. If the phosphorus were normal or elevated and triglyceride markedly raised, then the band contained very low density lipoprotein $S_{f}>100$ as well as the high

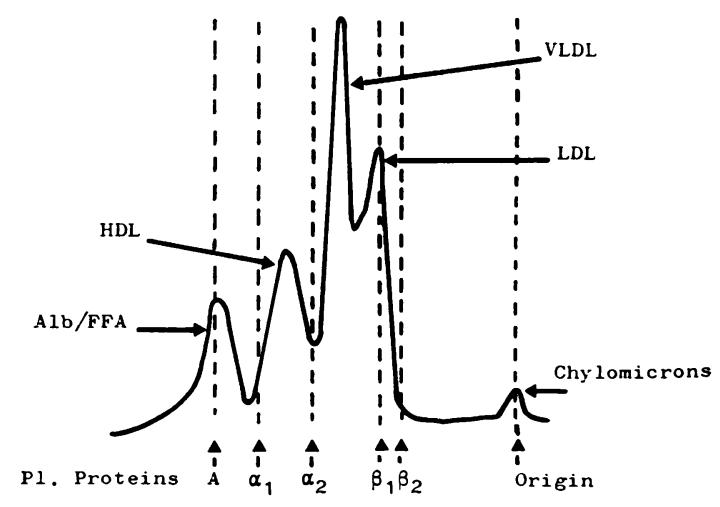

Fig. 3 An idealized Schiff's stained electrophoretogram demonstrating the positions of the five main lipoprotein bands.

density lipoprotein. This latter was occasionally observed despite the use of fasting samples, but the distinction is important, since these strips cannot be analysed quantitatively by this method.

\section{QUANTITATION OF ELECTROPHORETOGRAMS}

The arithmetic mean of the total lipoprotein for 13 samples determined by preparative ultracentrifugation was the same as that obtained by analytical ultracentrifugation (Table II) and individual samples agreed well.

Table III shows a a comparison of each lipoprotein level and its percentage content of total serum or plasma lipoprotein as found by preparative ultracentrifugation with refractometry and cellulose acetate electrophoresis. Good agreement of the results for the percentage of each component justify our initial assumption, and there is no need to introduce correction factors to account for differences in unsaturation between the classes of lipoprotein. Hence, for the Schiff reagent the intensity of staining appears to be directly related to the amount of lipid present.

\begin{tabular}{|c|c|c|c|c|}
\hline Series & No. of Samples & Method & $\begin{array}{l}\text { Total Lipoprotein } \\
(\mathrm{mg} / 100 \mathrm{ml})\end{array}$ & $\begin{array}{l}\text { Correlation }{ }^{1} \\
\text { Coefficient }\end{array}$ \\
\hline 1 & 13 & $\begin{array}{l}\text { Analytical ultracentrifuge } \\
\text { Preparative ultracentrifuge and refractometry }\end{array}$ & $\begin{array}{l}1,109 \pm 63 \cdot 7^{2} \\
1,087 \pm 62 \cdot 7\end{array}$ & 0.970 \\
\hline 2 & 83 & $\begin{array}{l}\text { Preparative ultracentrifuge and refractometry } \\
\text { Phosphorus and triglyceride estimations } \\
\text { Cholesterol and triglyceride estimation }\end{array}$ & $\begin{array}{r}943 \pm 53 \cdot 8 \\
958 \pm 55 \cdot 9 \\
1,000 \pm 75 \cdot 6\end{array}$ & $\begin{array}{l}0.924 \\
0.898\end{array}$ \\
\hline
\end{tabular}

Table II Comparison of cellulose acetate electrophoresis method with analytical and preparative ultracentrifuge methods

${ }^{1}$ Comparison between the first method in each series, and the others. All coefficients were significant at $\mathbf{P}<0.001$.

2Standard error of the mean. 
Table III Comparison of results of lipoprotein analysis of 59 samples by cellulose acetate electrophoresis and preparative ultracentrifuge methods ${ }^{1}$

${ }^{1}$ No significant difference was found between the two methods.

${ }^{2}$ Standard error of the mean.

$$
S_{\mathbf{f}} \text { rate }
$$

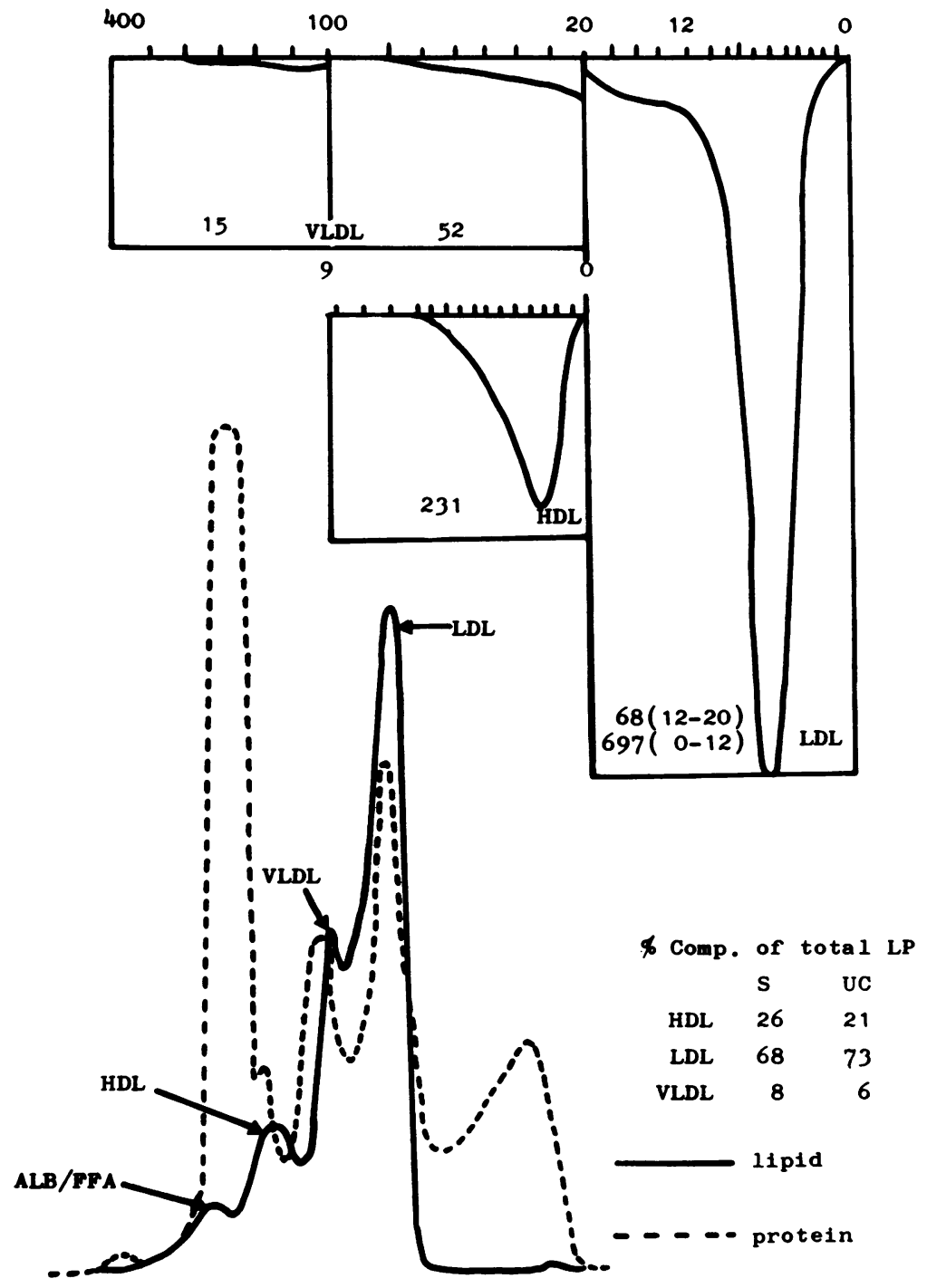

Fig. 4 Samples with a high concentration of low density lipoproteins with normal high density lipoproteins and very low density lipoproteins. ${ }^{1}$

${ }^{1}$ The frames contain tracings of the schlieren patterns, above which are figures representing the $S_{f}$ (or $F_{1.21}$ for the high density lipoproteins) range. The figures within each frame are the results of lipoprotein assay by analytical ultracentrifugation. Below the frames are densitometric tracings of the stained cellulose acetate electrophoretograms. The continuous line represents the lipoprotein trace, the broken line represents the total protein. The table on the right of the tracings compares the assays by analytical ultracentrifuge and the Schiff's stained electrophoretogram (S). 

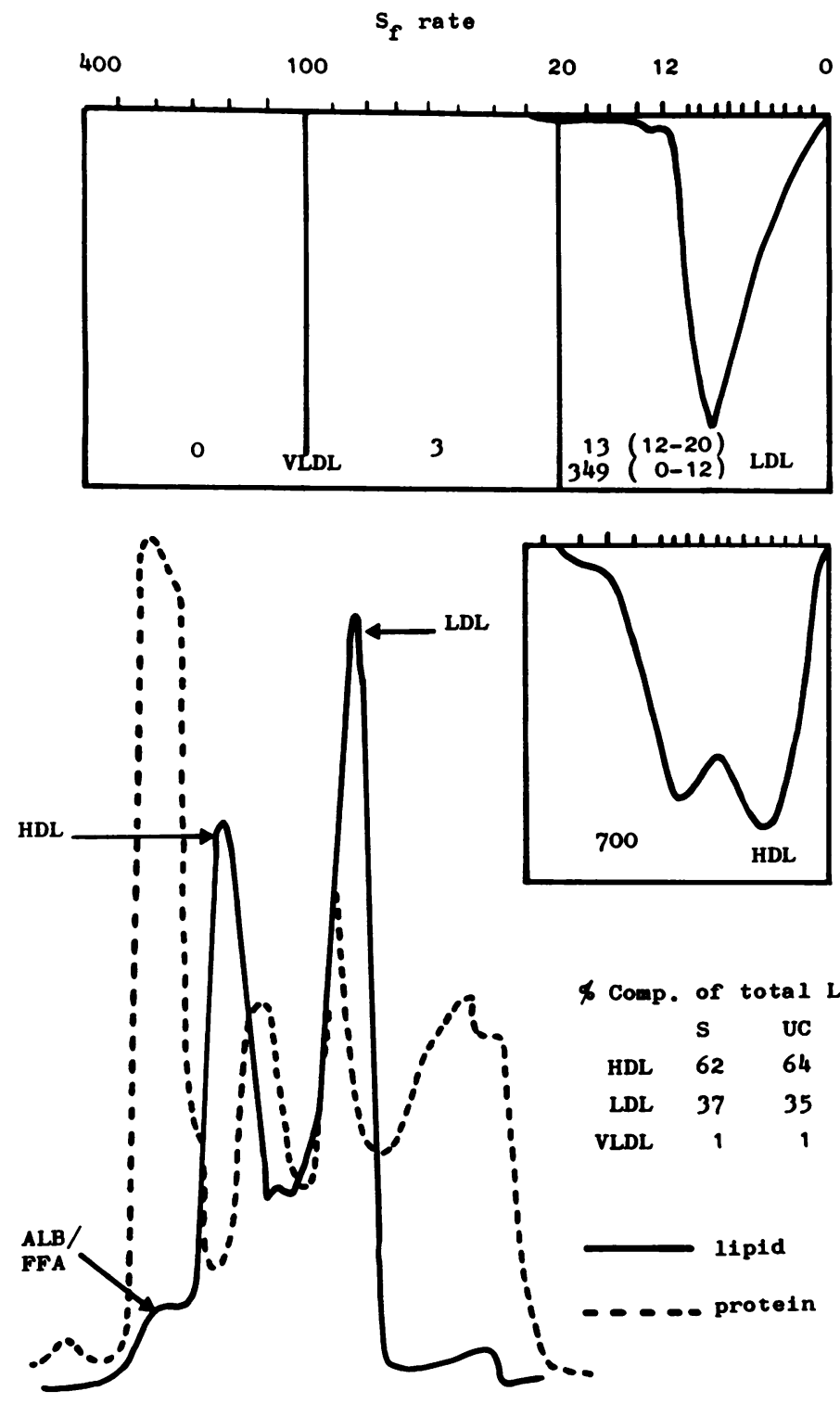

Fig. 5 Sample with a high concentration of high density lipoprotein and slightly raised low density lipoprotein and low very low density lipoproteins (see footnote to Figure 4).

A few electrophoretograms, $8 \%$ (seven of 90 ), did not agree where a very low density lipoprotein overlaid a high density one, or where one or more classes of lipoprotein possessed anomalous migration characteristics despite its apparent normality when $\Rightarrow$ examined in the analytical ultracentrifuge. Such $\stackrel{?}{?}$ electrophoretograms were not included in Table $\mathrm{C}$ III.

Figures 4-6 illustrate several aspects of the study $\frac{\overline{\bar{s}}}{\frac{7}{2}}$ of numerous plasma samples. The cellulose acetate $\propto$ electrophoretogram in Fig. 4 shows a four-peak lipo-» protein tracing with each peak in the expected position. $\vec{O}$ The appearance of a relative increase in low density lipoprotein is consistent with the percentage com- $\vec{\omega}$ position (S). Lipid assays (not presented here) showed a raised cholesterol and phosphorus witho a normal triglyceride level, thus confirming then apparent low very low density lipoprotein con-co centration. The schlieren analytical ultracentrifuge patterns provide added confirmation, demonstrating a two-fold rise in the low density lipoprotein concentration above normal, mainly of the $S_{\mathrm{p}} 0-12-$ type, with normal levels of both very low and high density lipoproteins.

In Fig. 5 the cellulose acetate electrophoretogram $\frac{}{3}$ again shows four peaks in the expected positions, but $\Phi$ there is a marked increase in the $\alpha_{1} / \alpha_{2}$ peak and $a-\vec{\theta}$ diminution in the $\alpha_{2} / \beta_{1}$ peak. This pattern suggests increased high and decreased very low density. lipoprotein concentrations. Lipid assays revealed large increases in phosphorus and cholesterol levels, but a low triglyceride level, thus confirming that the $\alpha_{1} / \alpha_{2}$ peak is due to high density lipoprotein. The lipid composition was worked out on this basis and $\stackrel{\mathbb{Q}}{\mathscr{2}}$ the results were in complete agreement with those $\overrightarrow{\hat{O}}$ obtained by analytical ultracentrifuge and schlieren 3 pattern analysis. The small peak in the $\alpha_{2} / \beta_{1}$ region appears to represent part of the high density lipoprotein complex.

The cellulose acetate electrophoretogram in Fig. 6 is almost identical with that in Figure 5. The lipid analyses, however, revealed a markedly raised triglyceride level with only moderate rises in the levels of phosphorus and cholesterol. This suggested that the large $a_{1} / a_{2}$ peak on the cellulose acetate electrophoretogram was due predominantly to very $\frac{?}{0}$ low density lipoprotein. The analytical schlieren patterns on ultracentrifugation demonstrated a great $N$ rise in very low density lipoprotein concentration, $N$ particularly in the $S_{f}$ range 0-400, with a low level of high density lipoprotein. This cellulose acetate ${ }^{\omega}$ electrophoretogram was not amenable to percentage analysis because the position of the high density ${ }^{\circ}$ lipoprotein could not be exactly identified.

Table III gives a comparison of results obtained $\stackrel{\text { ? }}{+}$ with cellulose acetate electrophoresis, with very low -0 density lipoprotein correction where necessary, and $\underset{\mathbb{D}}{\mathrm{D}}$ the preparative ultracentrifugation. The mean $\frac{?}{\mathbb{D}}$ values are in good agreement. 


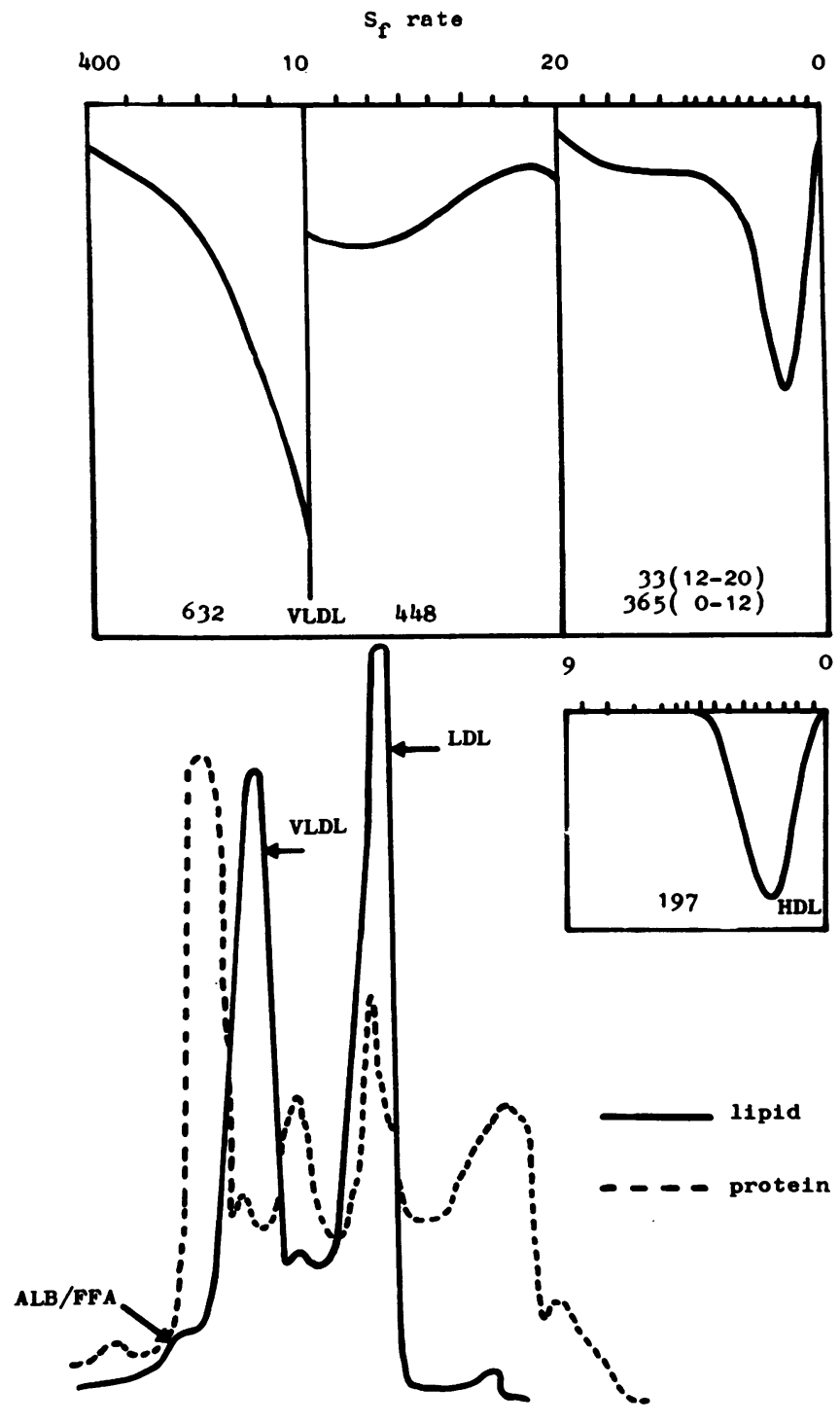

Fig. 6 Sample with a high very low density lipoprotein, normal low density lipoprotein, and with high density lipoprotein difficult to identify (see footnote to Figure 4).

\section{Discussion}

The new cellulose acetate electrophoresis method provides a simple and rapid determination of the percentage of the three main classes of lipoprotein in plasma and serum. In addition lipid assays assist in converting these percentages to absolute amounts of lipoprotein in all but a few cases.
The ozone-Schiff reaction was chosen for staining the electrophoretograms because it is quantitative and specific for lipoprotein. In contrast, fat-soluble dyes, such as Oil Red $O$ and Lipid Crimson, are not quantitative because they are not specific for lipid and much of the lipid content of the lipoprotein is lost during the staining procedure (Blaton, personal communication). Whole plasma and serum were found suitable for cellulose acetate electrophoresis, and it was not necessary to dialyse or separate lipoproteins by ultracentrifuge or other techniques before assay.

In order to develop cellulose acetate electrophoresis into a quantitative method, several assumptions were made, in particular that the number of fatty acid carbon-carbon double bonds available for reaction per unit mass of total lipid was the same for all classes of lipoprotein. Such was the case with a large range of different lipoprotein concentrations examined. The direct proportionality between staining and lipid content might not be true in extreme situations where the unsaturation between high, low, and very low density lipoproteins was widely different, and investigators using the cellulose acetate electrophoresis method in other species or in human disease where the lipid composition may be very abnormal might be advised to standardize the method against ultracentrifugation as was done here. In $8 \%$ of this series interpretation of the electrophoretogram was difficult because of an anomalous lipoprotein with unexpected migration characteristics but a normal analytical schlieren pattern profile on ultracentrifugation. Such abnormalities must result from alterations in charge density on the lipoprotein surface presumably due to the presence of different types of protein, phospholipids, or adsorbed fatty acid. One can speculate that this might be caused by a change in the apolipoprotein structure (Alaupovic, 1968) or to unusual binding to other plasma proteins. Further work is needed to examine this problem and a study of patients with abnormally migrating lipoproteins may be of some importance.

This method of lipoprotein assay is more rapid than many others which provide the same information. One technician can complete the analysis of 24 samples in two days. The most likely source of difficulty is the interpretation of an occasional abnormal electrophoretogram. In most cases the calculation of the total lipoprotein can be obtained from a phosphorus or cholesterol assay. We preferred the former because it gave a better correlation and the analytical method was more reliable. For samples with high very low density lipoprotein, it was necessary to apply a correction factor obtained from a triglyceride assay. 
Despite the numerous assumptions made in the quantitation of cellulose acetate electrophoresis, the method gave results which were remarkably accurate, and the technique is quite adequate for the screening of large numbers of samples for which it was devised.

\section{References}

Alaupovic, P. (1968). Recent advances in metabolism of plasma lipoproteins: Chemical aspects. Progr. biochem. Pharmacol., 4, 91-109.

Babson, A. L., Shapiro, P. O., and Phillips, G. E. (1962). A new assay for cholesterol and cholesterol esters in serum which is not affected by bilirubin. Clin. chim. Acta, 7, 800-804.

Bartlett, G. R. (1959). Phosphorus assay in column chromatography. J. biol. Chem., 234, 466-468.

Blaton, V., Peeters, H., Gresham, G. A., and Howard, A. N. (1968). Differential fatty acid composition of alpha and beta lipoproteins in baboons. Progr. biochem. Pharmacol., 4, 122-125.

Bodman, J. (1960). In Chromatographic and Electrophoretic Techniques, edited by Ivor Smith, vol. II, no. 4, p. 136. Heinemann, London.

Chin, H. P., and Blankenhorn, D. H. (1968). Separation and quantitative analysis of serum lipoproteins by means of electrophoresis on cellulose acetate. Clin. chim. Acta, 20, 305-314.

Cornwell, D. G. (1967). In Lipids and Lipidoses, edited by G. Schettler, pp. 168-189. Springer, New York.

Fletcher, M. J., and Styliou, M. H. (1970). A simple method for separating serum lipoproteins by electrophoresis on cellulose acetate. Clin. Chem., 16, 362-365.

Folch, J., Lees, M., and Sloane-Stanley, G. H. S. (1957). A simple method for the isolation and purification of total lipides from animal tissues. J. biol. Chem., 226, 497-509.

Fredrickson, D. S., and Lees, R. S. (1966). In Metabolic Basis of Inherited Diseases, edited by J. B. Stanbury, J. B. Wyngaarten, and D. S. Fredrickson, 2nd ed., pp. 434 and 452. McGraw Hill, New York.

Fredrickson, D. S., Levy, R. I., and Lees, R. S. (1967). Fat transport in lipoproteins: 'an integrated approach to mechanisms and disorders. New Engl. J. Med., 276, 34-44, 94-103, 148-156, 215-224, 273-281.

Kohn, J. (1961). A lipoprotein staining method for zone electrophoresis. Nature, 189, 312-313.

Kohn, J. (1966). Technique of cellulose acetate electrophoresis. Protides biol. Fluids, 13, 386.

Levy, R. I., and Fredrickson, D. S. (1965). Heterogeneity of plasma high density lipoproteins. J. clin. Invest., 44, 426-441.
Lindgren, F. T., and Gofman, J. W. (1957). Role of lipoproteins in coronary disease. Bull. schweiz. Akad. med. Wiss., 13, 152-178.

Lindgren, F. T., Hatch, F., and Freeman, N.K. (1967). In Proceedings of the Deuel Conference on the Fate of Dietary Lipids, edited by G. Cowgill and L. W. Kinsell, pp. 135. Public Health Service Publications, No. 742. U.S. Govt. Ptg Off., Washington, D.C.

Lindgren, F. T., and Nichols, A. V. (1960). The Plasma Proteins, edited by F. W. Putnam, vol. 2, p. 1. Academic Press, New York.

Lindgren, F. T., Nichols, A. V., Freeman, N. K., Wills, R. D., Wing, L., and Gullberg, J. E. (1964). Analysis of low-density lipoproteins by preparative ultracentrifugation and refractometry. J. Lipid Res., 5, 68-74.

Lofland, H. B., Jr. (1964). A semi automated procedure for the determination of triglycerides in serum. Analyt. Biochem., 9, 393-400.

Marsh, J. B., and Weinstein, J. B. (1966). Simple charring method for determination of lipids. J. Lipid Res., 7, 574-576.

Noble, R. P. (1968). Electrophoretic separation of plasma lipoproteins in agarose gel. J. Lipid Res., 9, 693-700.

Olson, R. E., and Vester, J. W. (1960). Nutrition-endocrine interrelationships in the control of fat transport in man. Physiol. Rev., 40, 677-733.

Papadopoulos, N. M., and Kintzios, J. A. (1969). Determination of human serum lipoprotein patterns by agarose gel electrophoresis. Analyt. Biochem., 30, 421-426.

Pearse, A. G. E. (1968). Histochemistry: Theoretical and Applied, 3rd ed., vol. 1, p. 437. Churchill, London.

Peeters, H., and Blaton, V. (1968). Lipid fatty acid relationships in electrochromatographic lipoprotein fractions. Progr. biochem. Pharmacol., 4, 144-152.

Quenouille, M. H. (1966). Introductory Statistics, 1st ed., p. 113. Pergamon Press, Oxford.

Skipski, V. P., Barclay, M., Barclay, R. K., Fetzer, V. A., Good, J. J., and Archibald, F. M. (1967). Lipid composition of human serum lipoproteins. Biochem. J., 104, 340-352.

Stamler, J., Berkson, D. M., Young, Q. D., Lindberg, H. A., Hall, Y., Mojonnier, L., and Andelman, S. L. (1963). Diet and serum lipids in atherosclerotic coronary heart disease. Etiologic and preventive considerations. Med. Clin. N. Amer., 47, 3-31.

Walton, K. W., and Darke, S. J. (1964). Immunological characteristics of human low-density lipoproteins. Immunochemistry, 1, 267277.

Winkelman, J., and Ibbott, F. A. (1969). Studies on the phenotyping of hyperlipoproteinemias evaluation of paper electrophoresis technique. Clin. chim. Acta, 26, 25-32.

Winkelman, J., Ibbott, F. A., Sobel, C., and Wybenga, D. R. (1969). Studies on the phenotyping of hyperlipoproteinemias: evaluation of cellulose acetate technique and comparison with paper electrophoresis. Clin. chim. Acta, 26, 33-39. 